\title{
LA DINÁMICA SOCIAL DE UNA COMUNIDAD FABRIL. \\ LA TRANSFORMACIÓN DE LA FÁBRICA DE HILADOS Y TEJIDOS DE ALGODÓN “SAN José Río HoNDo”, 1865-1902
}

Andrés García Lázaro*

\section{Resumen}

En este artículo se presenta un análisis de la comunidad que habitaba en la fábrica de hilados y tejidos de algodón, "San José Río Hondo", en Naucalpan, Estado de México; su conformación social, las actividades de sus integrantes y su transformación a lo largo de la segunda mitad del siglo XIX. La experiencia de "San José" permite hacer una aproximación al contexto fabril del estado durante los años de 1865 a 1902, conocer un estilo de vida rural, distinto al de las haciendas del altiplano, y observar los cambios tecnológicos que una fábrica de textiles mediana, como ésta, demandaba en la época.

Palabras clave: fábrica textil, comunidad fabril, porfiriato, Naucalpan, Río Hondo.

\section{Abstract}

In this paper an analysis of the community that lived in the spinning and knitting cotton factory, San José Río Hondo in Naucalpan, Estado de México: its social structure, the activities of its members and its transformation throughout the second half of the 19th Century is presented. The experience of "San José" allows to make an approach to the context of factories of the State during the years 1865 to 1902, to know about a rural life style different from that of the farms of the meseta and observe the technological changes that a medium textile factory, like this, required during that period.

Keywords: textile factories, factory community, porfiriato, Naucalpan, Río Hondo.

\footnotetext{
* Estudiante del doctorado en historia del Instituto Mora; andresgarcialazaro@gmail.com
} 
La historia de la industria en Naucalpan, Estado de México, inicia en 1866, con la fundación de la primera factoría de la entonces municipalidad: la fábrica de hilados y tejidos de algodón "San José Río Hondo". Esta fue una de las primeras cuatro empresas del ramo textil del algodón que existieron en la entidad, y dejó de funcionar en los años setenta del siglo xx.

La fábrica se fundó en una finca rural que, a pesar de las turbulencias políticas que experimentó el país a lo largo de la primera mitad del siglo XIX, había funcionado de manera ininterrumpida como molino de trigo y, al mejorar las condiciones económicas en México, cambió su giro por uno más rentable: los textiles, rubro que durante el gobierno del general Porfirio Díaz tuvo un gran impulso.

En "Río Hondo" habitaban franceses, españoles y mexicanos. Los primeros, unos cuantos apenas, con sus familias, formaban la punta de la pirámide social de la localidad, invariablemente ostentaron cargos de administradores o directores de la fábrica. Los españoles se encargaban del comercio de los textiles y eran los dueños de la tienda de abarrotes, aunque siempre fueron una minoría en el lugar, en la jerarquía local, se hallaron en segundo lugar. Finalmente, la base social de esta pirámide la formaban los trabajadores mexicanos y sus familias. Ellos constituían realmente la comunidad de "San José Río Hondo" y en ella se centran las siguientes páginas. ${ }^{1}$

La fábrica de hilados y tejidos "San José Río Hondo" llevó a cabo minuciosos registros poblacionales de la comunidad que habitaba en los límites de sus propiedades. En el Archivo Histórico de Naucalpan se conservan los registros correspondientes a los años 1865, 1870, 1882, 1883, 1885, 1887 y 1893. Se trata de padrones que incluyen número de habitantes por sexo y edad, estado civil, oficio y, en algunos casos, lugar de procedencia. Estos fueron elaborados por los administradores de "Río Hondo" a petición del gobierno local, quien a su vez, los utilizaba para informar el estado que guardaba la industria de la municipalidad. Generados también por la administración de la fábrica, existen censos del número total

1 La convivencia entre franceses, españoles y mexicanos debe haber estado atravesada por múltiples tensiones que traducían no solo un choque cultural, sino de clases. Sin embargo, en estas páginas centraremos nuestro análisis en la transformación de la estructura social de la comunidad de "San José" y no tanto en las tensiones sociales que la atravesaban. 
de habitantes en el lugar para los años de 1891 y 1896, así como de los asalariados con los que contaba la fábrica en 1902.

Con base en estos padrones es posible conocer la evolución de la comunidad de la fábrica a lo largo de casi 40 años: aumento o disminución de población, labores y oficios, demanda de mano de obra, etc. En resumen, estos registros proporcionan información suficiente para acercarse a una comunidad rural y fabril, a su conformación social, a las actividades de sus integrantes y a sus transformaciones durante la segunda mital del siglo XIX.

A su vez, la experiencia de "San José Río Hondo" permite una aproximación al contexto fabril del Estado de México durante la segunda mitad del siglo XIx; hace posible un acercamiento a un estilo de vida rural, distinto al que se daba en las haciendas del altiplano; también permite seguir los cambios tecnológicos que una fábrica de textiles mediana, como esta, demandaba en la época.

\section{De molino a fábrica}

La fábrica "San José Río Hondo" se construyó en una finca del rico hacendado Isidoro de la Torre, ${ }^{2}$ la cual había funcionado hasta entonces como molino de trigo, si bien en ella se desarrollaban además algunas actividades agrícolas y de pastoreo menor.

En este caso, como en tantos después de la mitad del siglo, el empresario textil de la ciudad de México y de los alrededores había buscado zonas rurales donde instalarse. Quería alejarse de la capital que por su diseño urbano, impedía la construcción de grandes centros industriales; entonces las fábricas que se comenzaron a establecer en la periferia de la capital

2 La familia De la Torre, una de las más ricas de la segunda mitad del siglo XIX en México, contaba con varias haciendas en las zonas de Morelos y el Estado de México, así como con fincas rústicas y urbanas en la capital y sus alrededores. Esta familia también fue propietaria de la fábrica de hilados y tejidos de algodón "San José Río Hondo" por más de cincuenta años en los que tres generaciones distintas de De la Torre estuvieron al frente de la misma. Isidoro de la Torre y Carsi, el patriarca del clan, nació en Cádiz, España, estaba emparentado con Francisco Antonio y José Ignacio de la Torre, comerciantes miembros del consulado de Veracruz, dueños de grandes fortunas generadas a finales del siglo XVIII. Según el historiador Luis Weckman, los De la Torre salieron del país durante la segunda ola de expulsiones de españoles en 1829, estableciéndose en Burdeos durante cuatro años hasta su regreso en 1833. Lo cierto es que para los años cuarenta, De la Torre y Carsi estaba inmiscuido en la política y el comercio de México. Weckman, Las relaciones franco-mexicanas, tomo I, p. 105. 
contaban con una característica fundamental: se construían según un patrón de "colonias industriales". Estas habían comenzado a establecerse desde 1830, distinguiéndose por su tamaño la fábrica textil "Hércules", en Querétaro. Este modelo fabril implicaba la construcción de industrias alejadas de las grandes ciudades, en terrenos rurales que resultaban más baratos que los urbanos y donde se buscaba la cercanía a un río para aprovechar la energía hidráulica. Una fábrica construida de acuerdo con este modelo contaban con todos los servicios para los trabajadores y sus familias, como: casas, escuelas, campos de cultivos y la tienda de raya, que pasó a ser un negocio más del centro fabril. Esto resultaba muy conveniente para el dueño de la empresa, ya que el ausentismo laboral era casi nulo y los gastos cotidianos de los trabajadores iban a parar a sus bolsillos. ${ }^{3}$ Este fue el modelo seguido por la familia De la Torre en "San José Río Hondo".

La empresa de los De la Torre, al cambiar su giro industrial — de molino a fábrica textil-, conservó sus actividades agrícolas y de pastoreo menor. Como era la usanza en la época y así convenía al patrón de colonia industrial adoptado, los trabajadores que se incorporaron a la producción fabril y sus familias se asentaron dentro de los terrenos de la propia fábrica. Con las nuevas actividades económicas aumentó el número de pobladores que vivían en la finca de tiempo atrás. Durante los primeros años de actividad textilera, la población local se multiplicó —en cinco años creció 21\% y, en los doce años siguientes se cuadruplicó-. Pero a fines de la década de 1880 la población local disminuyó de manera considerable y mantuvo esa tendencia en los siguientes años.

En 1865, un año antes de la transformación del molino en fábrica, los moradores de "Río Hondo" ascendían a 242 habitantes. ${ }^{4}$ Esta población estaba conformada por los trabajadores y encargados del molino y sus familias, de manera que en la finca vivían desde niños pequeños hasta ancianos de 70 años. La población mayoritaria en la finca en ese entonces era de jóvenes adultos — de entre 20 y 30 años—, seguida por niños — de 0

3 Para un acercamiento a este patrón de colonias industriales, véase Gómez Serrano, "Una ciudad pujante", p. 261; Trujillo, Operario fabriles, p. 71.

4 En el padrón de este año solo fueron registrados 164 varones, ni mujeres ni niñas aparecen empadronadas. Sin embargo, de los 164 trabajadores, 78 aparecen como casados, por lo que el número total de habitantes no debió ser inferior a 242. Éste es el único padrón donde no aparecen registradas las mujeres. AHN. Fondo Presidencia, vol. 7, exp. 24. 
Cuadro 1. Rangos DE EDAD

\begin{tabular}{c|c|c|c|c|c|c|c|c|c|c}
\hline & \multicolumn{7}{|c|}{ Rangos de edad } & \\
\cline { 2 - 11 } Años & $\mathbf{0}$ & $\mathbf{1 0}$ & $\mathbf{2 0}$ & $\mathbf{3 0}$ & $\mathbf{4 0}$ & $\mathbf{5 0}$ & $\mathbf{6 0}$ & $\mathbf{7 0}$ & $\begin{array}{c}\text { Total de } \\
\text { habitantes }\end{array}$ & Asalariados \\
& $\mathbf{a}$ & $\mathrm{a}$ & $\mathrm{a}$ & $\mathrm{a}$ & $\mathrm{a}$ & $\mathrm{a}$ & $\mathrm{a}$ & $\mathrm{a}$ \\
& $\mathbf{2}$ & $\mathbf{2 0}$ & $\mathbf{3 0}$ & $\mathbf{4 0}$ & $\mathbf{5 0}$ & $\mathbf{6 0}$ & $\mathbf{7 0}$ & $\mathbf{8 0}$ & \\
\hline 1865 & 30 & 37 & 47 & 28 & 17 & 2 & 3 & & 242 & 107 \\
\hline 1870 & 90 & 63 & 65 & 50 & 25 & 7 & 4 & & 304 & 102 \\
\hline 1882 & 170 & 112 & 170 & 112 & 54 & 12 & 6 & 1 & 637 & 212 \\
\hline 1883 & 121 & 91 & 134 & 86 & 47 & 18 & 5 & 3 & 505 & 88 \\
\hline 1885 & 139 & 84 & 114 & 82 & 63 & 24 & 6 & 5 & 517 & 86 \\
\hline 1887 & 115 & 80 & 61 & 60 & 48 & 16 & 1 & 2 & 383 & 85 \\
\hline 1891 & & & & & & & & & 351 & \\
\hline 1893 & 100 & 85 & 62 & 52 & 27 & 19 & 5 & 3 & 353 & 130 \\
\hline 1896 & & & & & & & & & 350 & \\
\hline 1902 & & & & & & & & & & 122 \\
\hline Promedio & & & & & & & & & 404 & 116 \\
\hline
\end{tabular}

Fuentes: AHN, Fondo Presidencia, vol. 7, exps. 21, 22, 23, 24; vol. 3, exps. 1, 3.

a 10 años—y “adolescentes"—de 10 a 20—. ${ }^{5}$ Efectivamente, en el molino vivía gente muy joven, $63 \%$ de la población estaba por debajo de los 30 años de edad. El 37\% restante de la población se distribuía entre los adultos: personas de 30 a 60 años de edad y ancianos mayores de 60 años. A partir de los 30 años de edad, los habitantes disminuían paulatinamente en número y pocos superaban el medio siglo de vida. ${ }^{6}$

Los oficios que se ejercían dentro de la finca en 1865 iban más allá de aquellos relacionados con la molienda del trigo. En la finca vivían y laboraban tejedores y "fabricantes" —el término se utilizaba para describir a todo trabajador dedicado a transformar las materias primas en manufactura, en este caso, posiblemente dedicado a hacer artículos para el hogar como ollas, vasijas y platos - estos dos grupos de artesanos formaban parte de la comunidad integrada en torno del molino, tanto como lo hacían el propio molinero y el panadero; además estaban quienes se ocupaban en actividades agrícolas, de construcción y reparación, o en servicios y pequeños comercios.

5 La palabra "adolescentes" es un anacronismo; la utilizamos aquí para una mejor agrupación de los rangos de edad.

6 Esta estructura de edades de la comunidad de "San José Río Hondo" era similar a la mayor parte del país. Véase González Navarro, El porfiriato. La vida social, p. 52. El promedio de vida en la ciudad de México para 1895 se calculaba en 31 años. 
Gráfica 1. Edad y población de “SAN José Río Hondo” en 1865

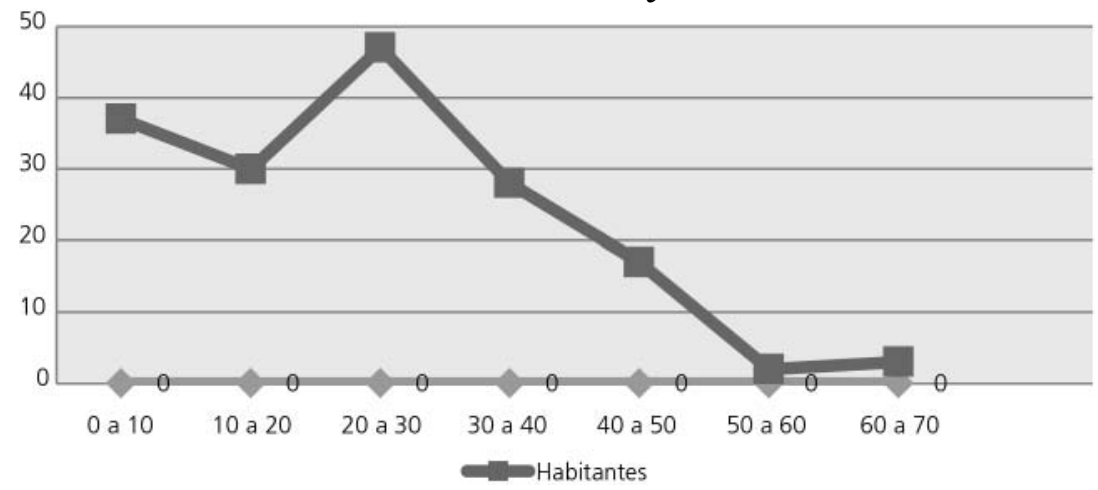

Fuente: AHN, Fondo Presidencia, vol. 7, exp. 24.

Efectivamente, la finca contaba con jornaleros, encargados de los cultivos a pequeña escala que había en "Río Hondo". Los granos que se sembraban en la localidad eran: maíz, frijol y cebada, en su mayoría para autoconsumo. ${ }^{7}$ Además, existía la figura del tlachiquero, encargado de la labor de raspar los magueyes para extraer el aguamiel con la que se fabricaba el pulque, y también un pastor responsable del cuidado de algunas cabras, burros y mulas. Había albañiles, ladrilleros, carpinteros y herreros, quienes tenían bajo su responsabilidad la construcción y reparación de la finca, así como el mantenimiento de la maquinaría del propio molino. Junto a estos, estaban los carretoneros, encargados de trasportar los desperdicios que el molino -y posteriormente la fábrica - generaba.

Finalmente, el carnicero y un comerciante — seguramente el tenderose sumaban al entramado social de la finca. Con ellos convivían el director, el administrador del molino y otros dependientes administrativos. Todos ellos en conjunto le daban vida a la comunidad de "San José Río Hondo". Ciertamente, los pobladores de "Río Hondo" constituían una sociedad rural, dedicados en su mayoría a las labores artesanales y otros más a las actividades del campo en pequeña escala.

De los 164 hombres registrados como habitantes de la finca en 1865, 107 recibían un pago por el trabajo que realizaban; desde luego que un buen

7 AHN, Fondo Fomento, vol.1, exp. 33. 
número de las personas restantes — niños, mujeres y ancianos — también colaboraban en las actividades económicas y en los servicios locales, aunque sin recibir remuneración. ${ }^{8}$ Sin embargo, esta situación, de falta de retribución a la labor de mujeres e infantes, se modificaría con el paso del tiempo. ${ }^{9}$

\section{El arranque de la fábrica}

Para 1870 — cinco años después, convertido el molino en fábrica一, la población local ascendía a 304 habitantes. Los niños habían aumentado al triple y se estableció un equilibrio entre adolescentes y adultos jóvenes, de tal forma que "San José Río Hondo" era una fábrica donde $71 \%$ de sus habitantes tenían a lo mucho 29 años. En cualquier caso, la población de adultos y ancianos también aumentó casi al doble en comparación con la de 1865.

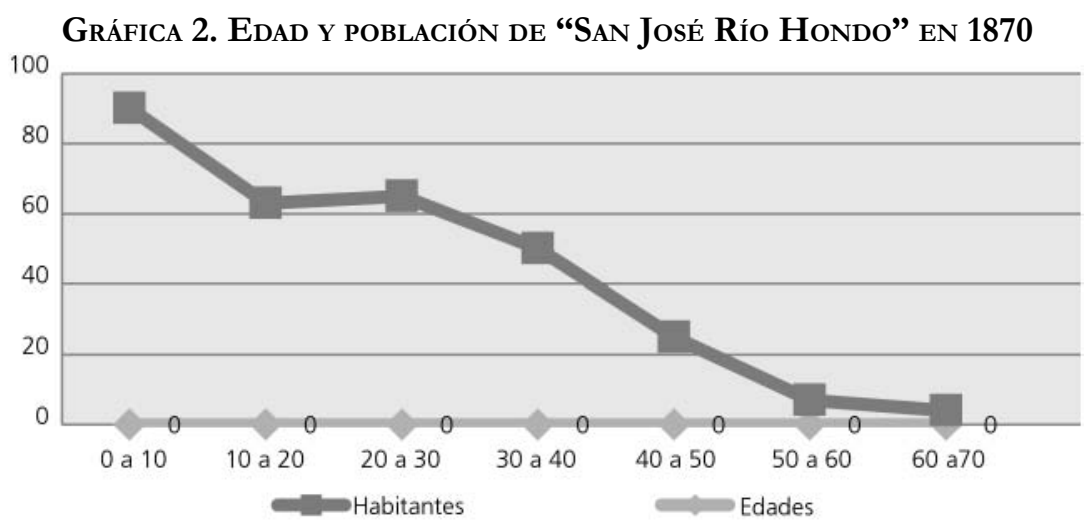

Fuente: AHN, Fondo Presidencia, vol. 7, exp. 21.

La trasformación del molino de trigo en fábrica textil representó cambios mayores. Hilados, tejidos y estampados requieren trabajadores con oficios muy diferentes a los que necesita un molino. Con todo, los dueños de "Río Hondo" mantuvieron las actividades que los pobladores desarrollaban. El

$8 \mathrm{Si}$ bien en otras regiones del centro de México, mujeres y niños recibían pagos, los que se registraban en libros distintos a los de la nómina principal, para el caso de la finca de "San José" no se ha localizado ningún tipo de registro paralelo.

9 En el padrón de 1887 aparecen formalmente mujeres y niños en la nómina de la fábrica. 
molino funcionó todavía varios años como parte de la nueva fábrica, los campos de cultivo también continuaron siendo explotados, y los burros y mulas - que en conjunto alcanzaban las 20 cabezas - siguieron presentes en el inventario de la empresa.

La familia De la Torre, al erigir la fábrica, conservó a muchos de los trabajadores de la antigua finca. El padrón de 1870 registra 56 nombres que se encontraban en el padrón de 1865, año en que la actividad central de la finca era el molino de harina. La mayoría de estos trabajadores eran artesanos, indudablemente acompañados de sus familias. La permanencia de casi la mitad de la población trabajadora de la finca como parte de la comunidad de la nueva fábrica respondía, en parte al menos, a los lazos paternalistas que se tendían entonces entre patrones y trabajadores y que, de alguna manera, comprometían a los primeros con el futuro de los segundos. Pero también, como apunta Stephen Haber, para una fábrica textil nueva era difícil encontrar obreros capaces: "existía un gran número de trabajadores no calificados, pero imperaba una escasez de trabajadores calificados como tejedores". ${ }^{10}$ En otras palabras, ante la dificultad de encontrar obreros especializados para la industria textil, se echaba mano de quien se tenía al alcance.

El año de 1870 fue una época de cambios en la conformación social de la comunidad de "San José Río Hondo": aunque varios habitantes del molino se mantuvieron, gente nueva había llegado al "vecindario". Se agregaron al entramado social de la comunidad nuevos oficios. Fue el caso del hojalatero, complemento ideal del herrero, necesario para mejorar el aspecto de las máquinas dañadas y evitar la humedad o corrosión de las mismas; ${ }^{11}$ los empleados domésticos y cocineros, al servicio del administrador, y los dependientes de la fábrica y sus familias; los maquinistas, encargados de la vigilancia y control del sistema hidráulico, de las máquinas de vapor y de las calderas, así como de la supervisión de las poleas que permitían la generación de energía para los telares. Se sumaron también los maestros de carda y telar; los primeros ocupados en la verificación del proceso de afelpado y peinado de las fibras de algodón, los segundos encargados de ins-

10 Haber, Industria y subdesarrollo, p.54.

11 Las definiciones de los oficios son Trujillo, Operarios fabriles, pp. 95-98. 
peccionar el buen acabado de los tejidos. Además, en el transcurrir de esa década, se agregó a la fabricación de hilados y tejidos la actividad del estampado, con el personal correspondiente dedicado a él.

La fábrica debió demandar para su arranque un gran número de manos, aunque la nómina de 1870 haya consignado únicamente a 102 trabajadores asalariados, es decir, 33\% de la población local. Sin duda, como en otras fábricas de la época, se aprovechaba el trabajo de niños y mujeres. La producción exigía una importante cantidad de mano de obra, porque el obrero calificado, adiestrado en la industria fabril y, por tanto, muy productivo, era escaso. Como Haber señala:

la productividad de la mano de obra mexicana era más baja que la de países industrializados, la clase trabajadora tenía sus raíces en el campesinado, muchos acababan de llegar del campo o iban y venían de la fábrica a la tierra. Por lo tanto, laboraban al ritmo del campesinado, un ritmo mucho más lento que el del proletariado industrial; los trabajadores se negaban a cambiar sus tradicionales hábitos laborales para aumentar la productividad o lograr una mayor disciplina en los centros industriales. ${ }^{12}$

Lo que podría significar, para el caso de la fábrica de "San José Río Hondo", que el trabajo de sus 102 asalariados y familiares sin paga hubiera podido ser realizado, incluso, con menos manos si se hubiera contado con una base de trabajadores industriales bien entrenados.

\section{Cambio demográfico y social}

El año de 1882 — trascurridos doce años después del segundo registro de habitantes de la fábrica - marca un momento de auge de "San José Río Hondo". En ese año se consignó la mayor cantidad de habitantes en la localidad. En comparación con 1865, los pobladores crecieron al cuádruple; en relación con 1870, se multiplicaron por más del doble. Las personas que vivían y trabajaban en la localidad en 1882 eran 637, de las cuales 212 eran remuneradas por sus servicios en la fábrica.

12 Haber, Industria y subdesarrollo, p.52. 
El grueso de la población de la comunidad en 1882, como en 1870 , lo conformaban los niños y adultos jóvenes; debajo de ellos estaban los adolescentes. Al sumarse esos tres grupos de edad, resultaba que $72 \%$ de las personas que vivían en la fábrica tenían menos de 30 años. Esta situación se mantuvo constante en los años posteriores. Aunque los registros de población muestran que había algunos trabajadores que llevaban casi 20 años en la finca, el que tras doce años el grueso de su población se haya mantenido por debajo de los 30 años de edad, sugiere que la fábrica de "Río Hondo" se convirtió en un lugar de vivienda temporal, donde nuevos grupos de trabajadores iban y venían constantemente.

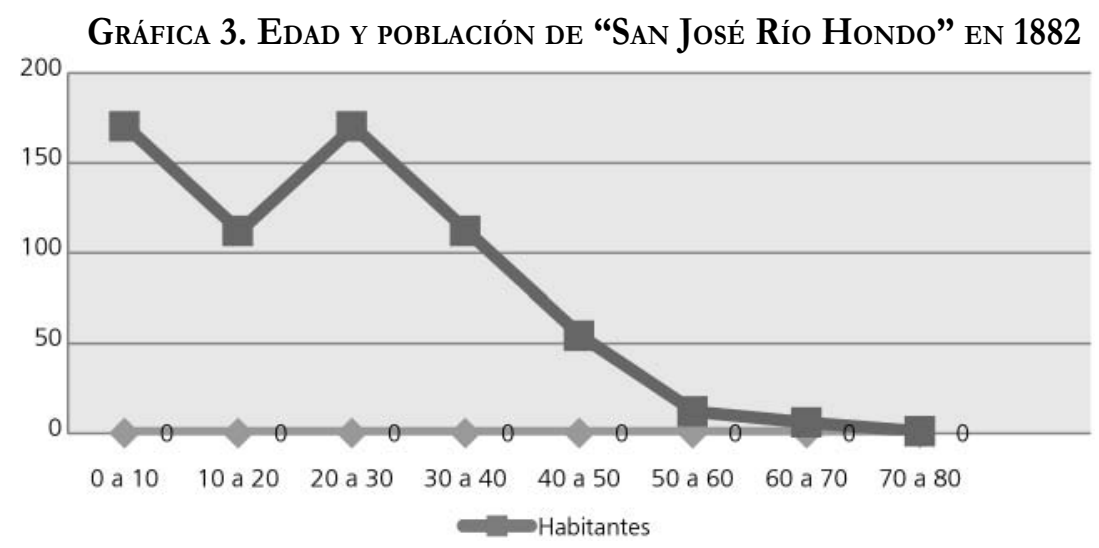

Fuente: AHN, Fondo Presidencia, vol. 7, exp. 21.

El historiador Mario Camarena Ocampo señala que la movilidad de los trabajadores textiles fue un elemento que los definió como clase. Durante el siglo XIX, éstos iban de una fábrica a otra en busca de mejores condiciones de vida y trabajo. En el caso de "Río Hondo", algunos trabajadores "originarios" de las fábricas textiles de Contreras y Miraflores iban a pasar temporadas a Naucalpan. ${ }^{13}$ De hecho, aunque se desconoce el nombre específico de las fábricas de donde venían, los registros poblacionales de "San José Río Hondo" indican como lugares de origen de varios de sus trabajadores las zonas textileras de San Ángel, Tlalpan y Querétaro. ${ }^{14}$

13 Camarena Ocampo, Jornaleros, tejedores, p. 46.

14 AHN, Fondo Presidencia, vol. 7, exps. 21 y 22. 
La emigración de los obreros respondía a varios factores. Muchos de ellos, eran trabajadores del campo que, al finalizar el ciclo agrícola, comenzaban sus actividades industriales o viceversa. Su movilidad respondía también a una búsqueda de fábricas que pagaran mejores salarios o a su despido cuando una factoría bajaba su productividad por escasez de agua, líquido indispensable para echar a andar la producción, o por baja demanda de sus productos en el mercado... ${ }^{15}$ También sucedía a la inversa que, ante la escasez de mano de obra, algunos industriales se dirigieran a otros en busca de hombres y mujeres para sus fábricas y lograran su apoyo para reforzar, al menos de manera temporal, su producción. ${ }^{16}$

Pero más allá de estas circunstancias, para esas fechas, la mayoría de los trabajadores de "San José Río Hondo" eran originarios de la fábrica: al menos $29 \%$ de ellos había nacido y crecido en la finca. A su vez, la empresa complementaba la nómina de sus trabajadores, más que con operarios de otras fábricas, con los pobladores de las comunidades cercanas a "Río Hondo": San Antonio, San Luis Tlatilco, San Esteban, San Rafael; todas estas en el municipio de Naucalpan. Como Camarena Ocampo apunta: "el trabajo fabril era una alternativa temporal a su actividad agrícola, creándose con frecuencia rutas de migración entre los lugares de origen de los trabajadores-campesinos y los lugares donde la industria se desarrollaba". ${ }^{17}$

En 1882 aparece el registro de "obrero" y "operario" dentro de la clasificación de los oficios que se practicaban en la fábrica. ${ }^{18}$ Antes, los registros hablaban de "fabricantes". Esto implicaba, indudablemente, un cambio en la manera de entender la relación trabajador-patrón. Parece posible afirmar que se modificaba el viejo trato paternal y se optaba por una mayor disciplina y un trato más impersonal; este cambio también nos habla de relaciones con trabajadores más especializados.

15 En tiempos de secas la fábrica de Río Hondo, por ejemplo, llegaba a parar hasta 27 horas a la semana, lo que repercutía en el bolsillo de los trabajadores. AHN, Fondo Presidencia, vol. 3 , exp. 16.

16 Camarena Ocampo, Jornaleros, tejedores, p. 68.

17 Ibid., p. 47.

18 Operario era la designación más común que en el siglo XIX se utilizó para referirse al obrero textil, el que en el registro se haga una diferenciación entre unos y otros posiblemente tenga relación con los salarios que percibían. 
Conforme la fábrica diversificaba su producción, crecía el número de maquinistas y de comerciantes. Se incorporó a la nómina de la empresa, el maestro de hilado, que fungía como supervisor de toda la fase de hilado, lo que supone una ampliación en ese departamento. Asimismo, aparecieron nuevos oficios en la lista del personal empleado como el químico, el grabador y el molinero, ubicados en el departamento de tintorería y estampados - cabe aclarar que el molinero se encargaba de moler las materias primas como el añil, palo de tinte y alumbre, que se utilizaban para el teñido de la fibra- Por otro lado, estos nuevos oficios implicaron una modernización en la producción, modernización que debió ser parcial, ya que el trabajo artesanal se mantuvo de manera significativa constituyendo $16 \%$ del trabajo remunerado por la empresa.

Un año después, en 1883, hubo cambios importantes dentro de la fábrica. De los 212 trabajadores que recibían remuneración por su trabajo en 1882, el número redujo a 88 . Este cambio repercutió de manera sensible en el tamaño de la comunidad local: el número de sus integrantes disminuyó de 637 a 505 personas, lo que significó una reducción de 21\%. La presencia en los registros de trabajadores de fogonero, gasero y encargado de regular el agua, habla del uso de máquinas de vapor en el proceso de producción, lo cual podría explicar la reducción de personal en "San José Río Hondo". La función del "aguador" iba más allá de acarrear el líquido; dicho trabajador estaba encargado de suministrar agua para la fábrica, a partir del control del líquido distribuido en tarjeas, acequias y presas, como el sistema de ruedas hidráulicas que permitían la generación de energía para los telares.

Sin duda, 1883 marcó también cambios en la ampliación de la gama de elementos producidos y diversificó los oficios a los que se dedicaban los trabajadores; apareció la figura del "bonetero". Aparte de mantas, debe haber empezado a producirse gorros, camisetas, calzones - lo que en la actualidad se denomina ropa interior-, en una cantidad importante, ya que los boneteros significaban $21 \%$ de la mano de obra remunerada, superada sólo por la de los tejedores y los jornaleros.

Surgieron también el "batanero", que ejecutaba la tarea de imbricar, apretar y unir lana y algodón con el objeto de dar textura y consistencia a las fibras al momento en que estas se entrecruzan para fabricar el hilo; el "devanador", quien hacía ovillos y enrollaba carretes con el hilo de las 


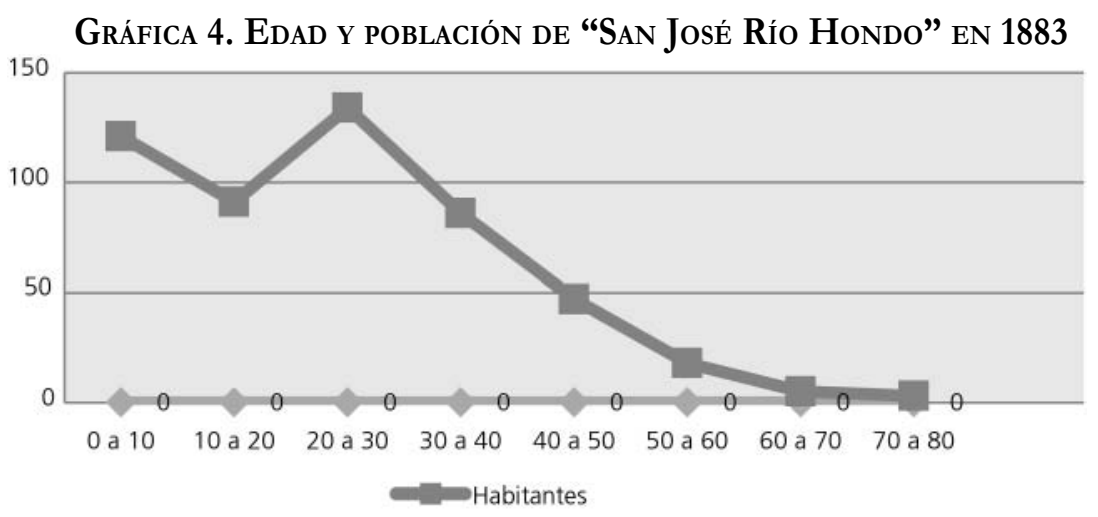

Fuente: AHN, Fondo Presidencia, vol. 7, exp. 21.

madejas que iban a ser teñidas en el departamento de tintorería; el "urdidor", que preparaba en bobinas y peines el conjunto de hilos que requería el telar para formar el tejido; el "doblador", asignado a plegar y hacer dobleces en las telas para que fueran estampadas; el "engomador" que aplicaba goma disuelta a las telas, con el propósito de que estas tuvieran lustre; y el "carretero", encargado del correcto funcionamiento de los husos y telares. El hecho de que dichos oficios hicieran su aparición en los registros en este año sugiere el uso de una maquinaria que necesitaba manos especializadas para su manejo. Esto implicó una menor participación de los artesanos en la producción de la fábrica. A partir de entonces, los artesanos o "fabricantes" —al menos con ese nombre genérico- fueron borrados de los padrones de la fábrica.

La modernización y el auge de "San José" se vieron reflejados en las cargas de trabajo y en el pago de los obreros. Era común que los operarios adultos se hicieran acompañar de sus hijos menores para enseñarles el oficio de hilandero, tejedor, tintorero, carpintero, hojalatero o maquinista. Los niños formaban parte integral del proceso productivo, realizaban además de las ya referidas, otras tareas como la limpieza y traslado de materia prima. ${ }^{19}$ Aparte, las mujeres a las que se les consideraba hábiles para la confección, muy probablemente fueron las boneteras encargadas de

19 Trujillo, Operarios fabriles, pp. 89-90. 
elaborar las camisetas, calzones, gorros y calcetines que se maquilaban en la fábrica.

Los salarios que se pagaban en "San José Río Hondo" eran de 3.5 reales para los adultos, de 2.8 reales las mujeres y de entre 1.05 a 1.26 reales para los niños. Calculados por día, los hombres ganaban 50 centavos, las mujeres 41 y los niños de 15 a 18 centavos. Se puede concluir, con seguridad, que para mediados de la década de los ochenta del siglo antepasado, el trabajo femenino e infantil era remunerado en "San José". Cuestión aparte eran los trabajadores del campo, que se encargaban de la producción agrícola de la finca, ellos ganaban 25 centavos diarios y los tlachiqueros, en la temporada que se les requería, 37 centavos. Estos salarios se mantuvieron así desde la década de los ochenta a principios del siglo $x x .^{20}$

\section{Cuadro 2. Salarios que se pagaban en "San José Río Hondo"}

\begin{tabular}{ccc}
\hline & Salario al día & Salario semanal/ 7 días a la semana \\
\hline Hombre & $50 c$ & 3.50 \\
\hline Mujer & $41 c$ & 2.87 \\
\hline Niño & $15-18 c$ & $1.05-1.26$ \\
\hline $\begin{array}{c}\text { Trabajador del } \\
\text { campo }\end{array}$ & $25 c$ & 1.75 \\
\hline Tlachiquero & $37 c$ & 2.59 \\
\hline
\end{tabular}

Fuente: AHN, Fondo Fomento, Vol. 3, Exp. 42.

Los montos pagados en "San José" estaban dentro del promedio del valle de México durante las mismas fechas, donde la escala de salarios para la industria textil iba de los 34 centavos diarios recibidos por peones y aprendices, hasta los 30 pesos que llegaban a ganar los empleados más calificados. A pesar de los abismos salariales entre los trabajadores de la fábrica, la paga que se recibía en la elaboración de textiles estaba por encima de la que prevalecía entre los peones agrícolas, que iba sólo de los 12 a los 36 centavos diarios. También sobrepasaba los sueldos de los trabajadores del ferrocarril, de los maestros de primaria y de los trabajadores de los molinos aledaños a la fábrica —-molino "Blanco" y "Atoto"-, donde se ganaba como máximo cuarenta centavos diarios. ${ }^{21}$

20 AHN, Fondo Presidencia, vol. 3, exp.1 y Fondo Fomento, vol. 3, exp. 6 y exp. 42. 21 Gutiérrez Álvarez, "La penosa existencia", p. 42; AHN, Fondo Fomento, vol. 3, exp. 42. 


\section{Comunidad equilibrada}

Las tendencias demográficas y de ocupación en la comunidad de la fábrica "San José Río Hondo" cambiaron muy poco en 1885. Por el contrario, en 1887, la población decreció 40\% y los niños menores de 10 años volvieron a ser la parte proporcional más grande de la población local: 30\% de los habitantes de la fábrica. Por su parte, la población en los rangos de edad que iban de los 20 a los 50 años encontró un equilibrio que en ninguno de los años registrados con anterioridad se había presentado. Estos grupos en conjunto, constituyeron 44\% de la fuerza laboral del centro fabril en 1887.

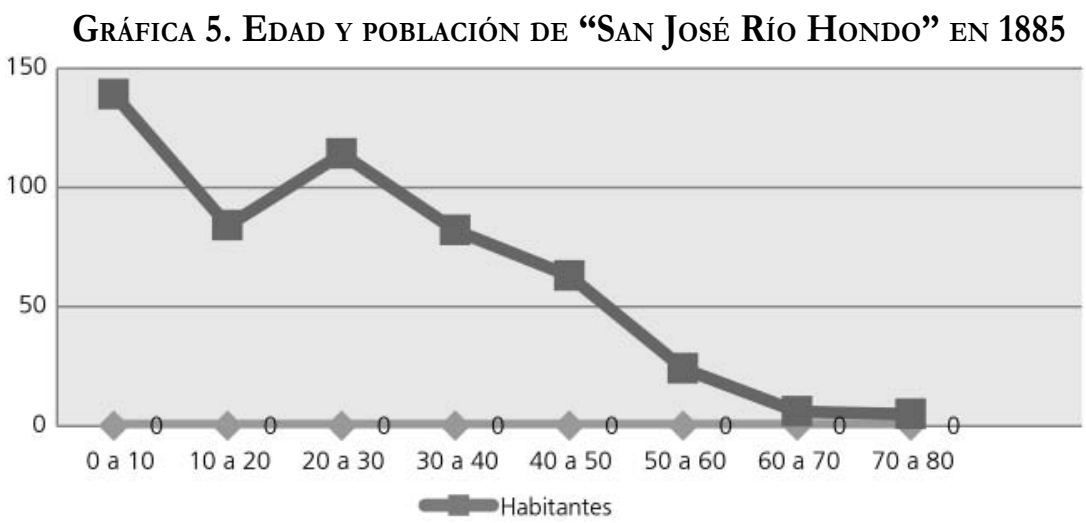

Fuente: AHN, Fondo Presidencia, vol. 7, exp. 22.

Gráfica 6. Edad y población de "SAN José Río Hondo" en 1887

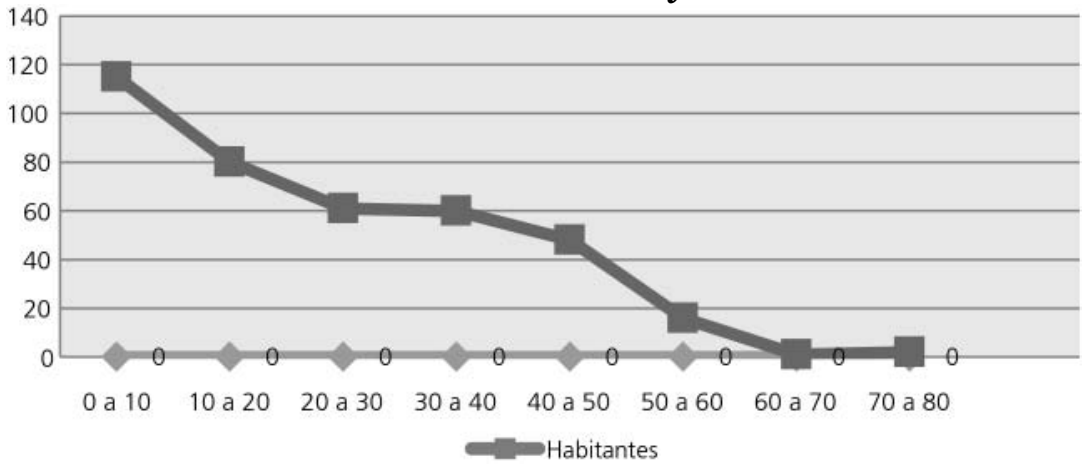

Fuente: AHN, Fondo Presidencia, vol. 7, exp. 22. 
Por otro lado, en ese mismo año, el número de adultos jóvenes se redujo casi a la mitad en comparación con los años anteriores, pero el número de niños se mantuvo constante. Es posible que esto solo traduzca un fenómeno de familias con descendencia más numerosa que antes, de suerte que, aun si la población adulta decrecía, la población infantil seguía una tendencia contraria.

El último registro de habitantes de la fábrica localizado permite seguir la transformación demográfica y de oficios de la localidad hasta el año de 1893. De acuerdo con este último padrón, los habitantes totales de la localidad disminuyeron $8 \%$ en comparación a 1887 , pero los trabajadores asalariados aumentaron 35\%. Estas cifras hablan de un aumento en la producción de la fábrica. Efectivamente, otras fuentes confirman que "San José Río Hondo" adquirió nueva maquinaria a principios de la década de $1890 .{ }^{22}$

En 1893 se puede encontrar una mano de obra más homogénea en "Río Hondo", a diferencia de los otros años, en que se registraba una gran diversidad en los oficios; la comunidad fabril estaba involucrada casi en su totalidad en las labores del tejido. En cuestión de 30 años, la antigua y diversificada comunidad rural se había transformado en una comunidad obrera, incorporada ya a un mundo capitalista.

Por otra parte, la composición por grupos de edad de la comunidad asentada en la fábrica de "San José Río Hondo" mantuvo la tendencia apuntada ya desde 1887, de acuerdo con la cual el número de pobladores decrecía según aumentaba su edad: muchos niños; cada vez menos adultos. Finalmente, el número de trabajadores asalariados registrados en 1893 fue bastante cercano al número de operarios y empleados remunerados que se presentaría en 1902, por lo cual es posible que las tendencias poblacionales se hayan mantenido igual o variado poco en los años que van de 1894 a 1901.

Al estudiar los cambios que sufrió la población de "San José Río Hondo" entre 1865 y 1902, se puede concluir que, durante los primeros años de la fábrica, se dio un crecimiento demográfico acelerado en el lugar. Así pareció haberlo demandado la puesta en marcha de la producción de textiles. Este crecimiento se detuvo en 1882 para dar lugar a una estabilización

22 АнА, саја 1256, exp. 17245. Entre 1891 y 1893 la fábrica modernizó su equipo. 
Gráfica 7. Edad y población de “SAN José Río Hondo” en 1893

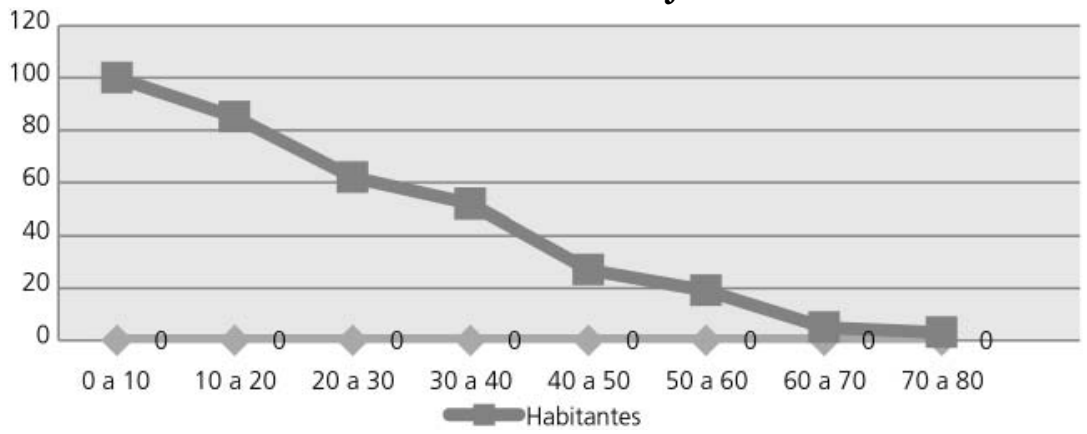

Fuente: AHN, Fondo Presidencia, vol. 7, exp. 23.

en el tamaño de la población, fenómeno relacionado posiblemente con la modernización de la producción de la empresa.

Si bien el padrón de 1865 excluye el número de mujeres en la finca, los registros posteriores dejan constancia de su presencia: las mujeres llegaron a ser $44 \%$ de la población total de la comunidad. De acuerdo con esos mismos registros, la mano de obra dominante en la producción fue siempre la masculina. Este es un aspecto que es importante destacar, ya que en otros centros fabriles se acostumbraba contratar un número mayor de mujeres, porque era mano de obra más barata. En cualquier caso, es necesario tener presente que los primeros registros pudieron haber ocultado un trabajo femenino sin remuneración.

Por lo que toca a la forma de conseguir y retener a sus trabajadores, la fábrica textil de "Río Hondo" procedía como las haciendas del centro de México; mediante una libre contratación de asalariados. Efectivamente, esta era una zona donde el peonaje por endeudamiento para los trabajos agrícolas había disminuido, ya que con la abundancia de mano de obra barata y sin compromisos, endeudar a los peones era innecesario. ${ }^{23}$ También parece haber sido innecesaria en "San José Río Hondo" la renovación constante del personal que laboraba en ella, ya que el ir y venir de una fábrica a otra por parte de los operarios, así lo sugieren.

23 Katz, La servidumbre agraria, pp. 37-38. 
Sin embargo, aunque hubiera habido esta migración de trabajadores es muy posible también que ellos hayan tenido un sentimiento de estabilidad laboral. Si las condiciones de trabajo hubieran sido poco favorables, tal vez, el número tan alto de niños en la localidad habría sido menor. Efectivamente, a lo largo de los 40 años recorridos, los infantes de cero a 10 años siempre fueron el grupo de población más alto dentro de la comunidad, incluso cuando hubo menos adultos.

Finalmente, la evolución social de la comunidad a lo largo de cuatro décadas muestra el paso de una población rural-artesanal-agrícola a una población aún rural, pero que tenía como actividad principal las labores industriales. Esto a su vez debió implicar un cambio en la manera de ver el trabajo. Al principio se contaba con una gran base de artesanos, dueños del producto de su trabajo; después se contó con una mayoría obrera, dueña ya solamente de su fuerza de trabajo. En otras palabras, la transformación de la comunidad significó la entrada de una sociedad de economía "tradicional" a una economía capitalista.

\section{Fuentes}

\section{Archivos}

AHN Archivo Histórico de Naucalpan, Naucalpan, Estado de México

AHA Archivo Histórico del Agua, México, D. F.

\section{Bibliografía}

Camarena Ocampo, Mario, Jornaleros, tejedores y obreros. Historia social de los trabajadores textiles de San Ángel (1850-1930), México, Plaza y Valdés, 2001.

Gómez Serrano, Jesús, "Una ciudad pujante. Aguascalientes durante el porfiriato", en Anne Staples (coord.), Historia de la vida cotidiana en México. Tomo IV. Bienes y vivencias. El siglo XIX, México, FCE/COLmeX, 2005, pp. 253-286.

González Navarro, Moisés, Elporfiriato. La vida social, vol. Iv, Historia moderna de México, $4^{\mathrm{a}}$ ed., México, Hermes, 1985. 
Gutiérrez Álvarez, Coralia, "La penosa existencia en las fábricas textiles de Puebla y Tlaxcala", en Anne Staples (coord.), Historia de la vida cotidiana en México. Tomo IV. Bienes y vivencias. El siglo XIX, México, FCE/COLMEX, 2005, pp. 527-562.

Haber, Stephen H., Industria y subdesarrollo. La industrialización de México 18901940, México, Alianza, 1992.

Katz, Friedrich, La servidumbre agraria en México en la época porfiriana, $4^{\mathrm{a}}$ edición, México, Era, 1984. (Problemas de México).

Trujillo Bolio, Mario, Operarios fabriles en el Valle de México (1864-1884). Espacio, trabajo, protesta y cultura obrera, México, COLMEX/CIESAS, 1997.

Weckman, Luis, Las relaciones franco-mexicanas (1823-1838), México, Secretaría de Relaciones Exteriores, 1961. 